\title{
Dilemmas and New Paradigms in Asthma Management
}

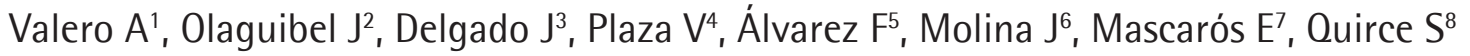 \\ 'Sección de Alergología, Servicio de Neumología y Alergia, Hospital Clínic de Barcelona, Universitat de Barcelona, IDIBAPS, CIBER de \\ Enfermedades Respiratorias (CIBERES), Spain \\ 2Unidad de Asma Grave, Servicio de Alergología, Complejo Hospitalario de Navarra, Pamplona and CIBER de Enfermedades Respiratorias \\ (CIBERES) \\ ${ }^{3}$ Unidad de Gestión Clínica de Alergología, Hospital Virgen Macarena, Sevilla, Spain \\ ${ }^{4}$ Servei de Pneumologia i Al-lèrgia, Hospital de la Santa Creu i Sant Pau, Institut d'Investigació Biomèdica Sant Pau (IIB Sant Pau), Universitat \\ Autònoma de Barcelona, Barcelona, Spain \\ "Unidad de Asma, Unidad Médico-Quirúrgica de Enfermedades Respiratorias (UMQER), Hospital Universitario "Virgen del Rocio", Sevilla, Spain \\ ${ }^{6}$ CS Francia, Dirección Asistencial Oeste, Fuenlabrada, Madrid, Spain \\ ${ }^{7}$ Centro de Salud Fuente de San Luis, Departamento Hospital Dr Peset, Valencia, Spain \\ ${ }^{8}$ Department of Allergy, Hospital La Paz Institute for Health Research (IdiPAZ) and CIBER de Enfermedades Respiratorias (CIBERES), Madrid, Spain
}

J Investig Allergol Clin Immunol 2019; Vol. 29(1): 15-23

doi: $10.18176 /$ jiaci.0345

\section{Abstract}

Asthma is one of the most common inflammatory diseases in the world. The main goal of treatment is to achieve optimal control. Although every patient is different, clinical practice guidelines can help physicians to manage the disease. However, the recommendations made by guidelines are not always identical, and the continuous release of new data on the various management strategies can mislead both patients and physicians.

We aim to summarize the main controversies in management and treatment recommendations in asthma guidelines, revise the most recent scientific evidence, and pinpoint possible solutions. We do not issue new recommendations or challenge evidence-based guidelines. We concluded that more tools are necessary to achieve and measure optimal asthma control and to better assess the impact of asthma on patients' lives. Also essential is a more accurate appraisal of the short-term and long-term effectiveness and safety of asthma therapies and the possibilities of successful immunomodulation.

Key words: Asthma control. Asthma management. Dilemma. Guidelines. Inhaled corticosteroids. Immunotherapy. Paradoxes. Treatment.

\section{Resumen}

El asma es una de las enfermedades inflamatorias más comunes en el mundo, y el objetivo principal de su tratamiento es lograr el mejor nivel de control en cada paciente. Aunque cada enfermo es diferente, se han desarrollado guías de práctica clínica nacionales 0 internacionales, con el objeto de ayudar a los médicos a controlar la enfermedad, de acuerdo a la mejor evidencia científica disponible. No obstante, las recomendaciones formuladas por las diferentes guías no siempre son iguales, y continuamente se están publicando nuevos datos sobre diferentes y nuevas estrategias de manejo de la enfermedad. Todo ello, puede inducir a error tanto a los pacientes como a los médicos. Nuestro objetivo con este artículo es, en primer lugar, revisar las principales controversias o dilemas, en términos de manejo y recomendaciones de tratamiento, que generan las guías de manejo del asma más difundidas; en segundo lugar, revisar la evidencia científica más recientemente publicadas y finalmente señalar posibles soluciones a estos dilemas. Esta revisión, sin embargo, no tiene como objetivo emitir nuevas recomendaciones o cuestionar las directrices u recomendaciones basadas en la evidencia, definidas en las guías. Como conclusión de este artículo, los autores consideraron que se necesitan mejores herramientas para alcanzar y medir el control óptimo del asma y para evaluar mejor el impacto del asma en la vida de los pacientes. Además, sería de suma importancia conocer con mayor precisión la efectividad y seguridad a corto y largo plazo de las terapias para el asma, y las posibilidades de una inmunomodulación eficaz. Palabras clave: Control del asma. Manejo del asma. Dilema. Guías. Corticosteroides inhalados. Inmunoterapia. Paradojas. Tratamiento. 


\section{Introduction}

Asthma is one of the most common inflammatory chronic diseases, affecting more than 330 million people worldwide. Its prevalence continues to grow in most countries-it now affects approximately $1 \%-18 \%$ of the world's population-and varies between developed countries (21\% in Australia) and developing countries $(0.2 \%$ in China) $[1,2]$.

As asthma is a chronic disease, the goal of treatment is to achieve optimal control, ie, minimizing symptoms and limitations in daily activity, preventing exacerbations, and improving lung function. However, control of asthma is not always easy to achieve, since each patient is different and treatment has to be adapted according to disease progress. Current guidelines, such as the Global Initiative for Asthma (GINA) [3] or the most recent version of the Spanish Guidelines for Asthma Management (GEMA) [4], aim to facilitate patient management. However, the recommendations issued by guidelines are not always consistent. Most patients with asthma can be categorized as having mild disease, which is precisely the degree of severity where recommendations for management and treatment are most controversial, thus leading to confusion for both patients and physicians.

In addition, a series of dilemmas in the management of asthma arise with respect to aspects such as the use of questionnaires, the indication of allergen immunotherapy, or the use of the combination of inhaled corticosteroids and long-acting $\beta_{2}$-agonists (ICS/LABA) as reliever treatment [5].

In this review, we discuss relevant controversies related to asthma treatment and aspects of asthma management that can prove paradoxical (Table) [6,7]. We also assess doubts and myths in the questionnaire-based assessment of asthma control, immunotherapy, and the benefits of therapy with ICS/LABA as reliever medication.

\section{Dilemma 1: Difficulties in Evaluating Asthma Control}

The main goal of asthma management today is the achievement and maintenance of optimal disease control. Both the GINA [3] and the GEMA [4] guidelines have defined the term control as effective management of the clinical characteristics of the disease, including symptoms, nocturnal awakening, reliever use, limitation of activity, and lung function, as well as future risk of adverse outcomes. Three levels of asthma control have been established (well controlled, partially controlled, and uncontrolled). Poor asthma control increases the future risk of exacerbations [8].

The most commonly used tools to assess asthma control are the Asthma Control Test (ACT) [9] and the Asthma Control Questionnaire (ACQ) [10], both of which can be compared based on the criteria used in GINA.

The ACT [9] and the ACQ [10] were developed to assess disease control at 1 week before consultation (ACQ) and 4 weeks before consultation (ACT) and are used worldwide. These questionnaires are simple and easily completed by patients and make it easy for clinical practitioners to assess how effectively asthma symptoms are controlled. Both have been adapted and validated in several languages, including Spanish. The scores in the ACT questionnaire range from 5 (worst control) to 25 (total control). The ACT is easy to apply and was specifically designed for use in clinical practice. The ACQ assesses 7 items, which include asking patients to recall their experiences in the previous week and to respond to questions about nighttime waking, symptoms on waking, limitations in activity, shortness of breath, wheezing, required use of shortacting 32 -agonists (SABA) for rescue, and $\mathrm{FEV}_{1} \%$ predicted before bronchodilator on a 7-point scale [5,8]. All these items are equally weighted. In the shortened versions (ACQ5 and ACQ6), the last 1-2 items can be eliminated.

Table . Main Dilemmas in Asthma Management

$\begin{array}{ll}\text { Dilemma } & \text { Description } \\ 1 & \begin{array}{l}\text { It is necessary to define the best tool for assessment of asthma control, because treatment relies on it. The ACT is } \\ \text { a validated questionnaire that seems to be very useful in clinical practice, although more studies are needed to } \\ \text { confirm its usefulness. }\end{array}\end{array}$

In step 1 of treatment, the combination of a SABA and an ICS is effective and safe, despite the fact that the current recommendation is still SABA in monotherapy.

ICS/LABA has proven to be more effective than SABA monotherapy for as-needed treatment in step 2, thus improving adherence to ICSs.

From step 2 onward, it is recommended to reduce the use of SABAs, which are precisely the drugs that provide the patient with the greatest relief.

5 Many studies have proven that MART is safer and more effective than SABAs. However, guidelines still consider SABA monotherapy the reliever treatment of choice.

Immunotherapy is only accepted in mild-moderate asthma patients. However, some studies support the safety and effectiveness of immunotherapy in poorly controlled asthma patients.

Allergic and nonallergic asthma differ in etiology and in some aspects of treatment and management. However, international guidelines do not differentiate between the 2 types.

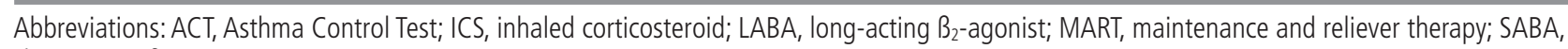
short-acting $B_{2}$-agonist. 
In the ACT questionnaire, one of the questions is on the use of relief medication (salbutamol or terbutaline), although there is no mention of the possible use of combination therapy with ICS/LABA as rescue medication, which in some circumstances has been proven to be more effective, both in adults and in children [11].

During the past few years, numerous studies have confirmed the importance of exacerbations in control and prognosis of asthma. In fact, the presence of at least 1 exacerbation in the previous year is considered to be a key risk factor for new exacerbations, and the presence of exacerbations is considered to be the most important risk factor for the worsening of lung function [12]. These factors would facilitate the presence of new exacerbations in a progressively worsening vicious cycle. However, the presence of moderate and severe exacerbations, for which clinical data are easy to obtain, is not included in any of the questionnaires used to assess asthma control $[9,10]$, although it is included in the guidelines [3,4], which clearly state that an exacerbation during the previous year indicates lack of control.

As time goes by, there is more and more interest in e-health and computerized management, and paper questionnaires may seem anachronistic. A computerized approach to these questionnaires has been envisaged [13], and web-based management seems feasible, safe, and preferred by patients, with no significant differences in clinical outcomes between the web-based and paper-based approaches.

Apart from considering these instruments to assess control and adherence, there are no specific indications or suggestions as to which of these questionnaires should be chosen in clinical practice.

We must also question the reliability of clinical practice guidelines, because sometimes, even if the recommendations of a clinical guideline are followed carefully, asthma may remain uncontrolled, as in the COAS study [14], where the objective was to achieve control in patients with uncontrolled asthma by following the recommendations of GINA 2010. Even with optimal treatment, most patients did not achieve optimal control according to the GINA criteria. The risk factors identified were older age, higher body mass index, greater disease severity, longer disease course, and worse lung function.

In the study by Olaguibel et al [15], the objective was to evaluate which cut-off points from the ACQ questionnaire best indicate the level of asthma control according to GINA. Among 1363 asthmatic patients, $13.6 \%$ were controlled, $34.2 \%$ partially controlled, and $52.3 \%$ uncontrolled. The ACQ cutoff points that best agreed with GINA-defined asthma control were $\mathrm{ACQ}<0.5$ for "controlled asthma" (sensitivity, 74.1\%; specificity, 77.5\%) and ACQ $\geq 1$ for "uncontrolled asthma" (sensitivity, 73\%; specificity, 88.2\%) [15].

A meta-analysis [16] comparing the efficacy of ACT and ACQ in 21 studies covering 23624 patients that examined the accuracy of the ACT, ACQ, or both in the assessment of asthma control. The results showed that ACT had good diagnostic accuracy for assessment of controlled and poorly controlled asthma and that ACQ had good diagnostic accuracy for assessment of poorly controlled asthma at the cut-off points specified above. The authors concluded that ACT is preferable to the ACQ in clinical practice and that the ACQ requires further cross-validation.

There is little agreement on disease control between patients and physicians or between physicians and validated questionnaires/established guidelines. Consequently, wellcontrolled asthma is overestimated by patients and physicians, indicating excessive optimism that can lead to erroneous indications and treatments $[6,17]$.

Vennera et al [18] evaluated agreement between the perception of disease control by patients and physicians (according to the GEMA guidelines) and found that both overestimated control (75.8\% and 59.3\%, respectively). However, asthma was not controlled according to the GEMA criteria, and only $10 \%$ of patients with severe asthma were controlled according to the GEMA criteria.

The reasons these perceptions differ were examined by Bidad et al [19], who found that patients' self-management was influenced by their perceptions of asthma and its treatments. Sometimes, symptoms indicative of poor control were often tolerated as part of living with asthma.

In conclusion, it is necessary to define the optimal tool for assessing asthma control, because treatment is prescribed based on its findings. ACT is a validated questionnaire that is very useful in clinical practice, although more studies are required to confirm this usefulness.

\section{Dilemma 2: Treatment in Step 1: SABA or LABA (Fast Acting)/ICS?}

The severity of asthma is categorized mainly as mild in steps 1 and 2, and it is precisely these steps that are the most controversial. The use of SABAs as rescue treatment in mild asthma (steps 1 and 2) is open to debate.

All guidelines and most physicians usually recommend as-needed SABAs for quick relief of symptoms. However, SABAs do not reduce the risk of flare-ups and do not treat inflammation. Besides, regular use of SABAs leads to rapid $\beta_{2}$ receptor tolerance, rebound bronchoconstriction, and even increased inflammation. In addition, importantly, we do not have long-term safety data on SABA in monotherapy.

Inflammation is the underlying mechanism of asthma, irrespective of the treatment step; therefore, treating inflammation should be the main goal in all asthma steps, not only the severe ones. If we aim to ensure good control from the initial steps, we should be much more effective from the beginning [5].

While recent studies support the use of ICS/formoterol on demand as being more effective for controlling symptoms in the initial asthma steps, the main guidelines have not yet changed their recommendations.

Although these studies involved patients in step 2, some authors [5] suggest that ICSs as needed could also be used in step 1. Adding an ICS as needed in all patients with asthma, even in step 1, may help to relieve symptoms and reduce the frequency of exercise-induced bronchoconstriction, as well as the risk of serious exacerbations and subsequent decline in lung function [5]. Given the poor adherence to ICSs in monotherapy (because patients do not feel rapid relief), adding 
the combination of a fast-acting LABA (ie, formoterol) and ICS from step 1 has been proposed $[4,6,7]$.

A recently published study [20] summarized the new lines of treatment in step 1 of asthma. The authors explain that the recommendation of ICSs at step 1 is an innovative, evidencebased decision for several reasons. First, studies have shown ongoing airway inflammation and airway remodelling. Second, elevated exhaled nitric oxide levels and bronchial biopsy evidence of airway inflammation have been found in patients with mild intermittent asthma. Third, bronchoconstriction generates excessive mechanical forces within the airways that distort tissue cells. Finally, this phenomenon might occur every time asthmatic patients inhale SABAs as needed.

Therefore, early initiation of low-dose ICSs significantly improves lung function.

Moreover, treatment with LABAs alone is expressly contraindicated, even as reliever medication. The same argument could be applied to SABAs.

This issue has been addressed in children. For example, Du et al [8] performed a meta-analysis in which only the studies addressing symptoms in children were included. The authors concluded that 3 months of treatment with ICSs significantly increased the number of children without asthma symptoms compared with placebo. However, the same study showed that the effects of ICSs on lung function compared with placebo or leukotriene receptor antagonists (LTRAs) were almost the same in terms of airway hyperresponsiveness, airway inflammation, symptom control, and adverse effects (in patients with mildintermittent asthma).

In 2005, Boushey et al [21] were the first authors to demonstrate that in mild asthma, treatment with intermittent on-demand ICSs was as effective as continuous treatment with an ICS or an antileukotriene in terms of control of exacerbations. In 2007, Papi et al [22] performed a doubleblind placebo-controlled study and found that, depending on the patient's symptoms, a combination of salbutamol and beclomethasone $(250 \mu \mathrm{g})$ in the same aerosol was as effective (in terms of control of exacerbations) as twice-daily inhaled beclomethasone, despite the fact that the cumulative dose of ICS in the combined on-demand treatment group was 4 times lower. Similarly, in 2012, Calhoun et al [23] did not find significant differences in the efficacy of treatment with intermittent ICSs (simultaneously with the rescue SABA), compared with patients who used ICSs daily, although the cumulative dose of ICS in the first group was also significantly lower.

Asthma is a chronic and variable disease whose chronicity is determined by the level of inflammation and whose variability is due to bronchospasm. Likewise, treatment for inflammation is almost exclusively with ICSs, whereas that of bronchospasm is based on SABA. Applying only 1 of these treatments means that one of the pathophysiological characteristics of asthma goes unassessed.

SABAs are short-acting drugs with a mechanism of action limited to bronchodilation. Recommending them as the only treatment in step 1 , just when symptoms appear, shows asthma to be an acute disease. This concept, which is rooted in the patient, makes it difficult for the patient to correctly follow maintenance treatment in more severe stages of the disease.
To conclude, in step 1 of asthma treatment, ICS/LABA can be more effective as on-demand treatment than a SABA alone, because it helps to reduce inflammation and the risk of exacerbations.

\section{Dilemma 3: Step 2, Carrying Over Habits From Step 1}

Dilemma 3 is very similar to the Dilemma 2, in that it involves the same behaviour as in step 1, namely, the use of SABAs as needed in mild asthma (step 2) instead of ICS/ LABA. The use of SABAs as reliever treatment promotes the belief that asthma always has to be managed with SABAs as the only rescue treatment and not with ICS/LABA as needed. This belief is subsequently difficult to eradicate in severe cases $[4,7,24]$.

Moreover, as we mentioned previously, adherence to ICSs is very poor in both adults and children, with an estimated average dispensing coverage of $<25 \%$ of days [25]. From the patient's point of view, SABAs are cheaper, quicker, more effective, and safer (corticosteroid panic). These qualities make SABAs the patient's treatment of choice.

The fact that maintenance and reliever therapy (MART) is more effective than SABA monotherapy for relief of symptoms has been proven not only in adults, but also in adolescents, with similar results [26]. Asthma is one of the most common chronic diseases in children and adolescents, and its considerable variability during these years hampers management. In this specific subgroup, adherence to ICSs is even poorer, with an increased risk of exacerbation. Jorup et al [26] performed a clinical trial with 1847 adolescents (aged 12 to 18 years) and found that budesonide-formoterol as needed was similar to comparators for the primary endpoint (time to first severe exacerbation). The results were similar for the secondary endpoint, ie, no superiority with respect to the total number of severe exacerbations, asthma symptoms score, nighttime awakenings, as-needed inhalers, $\mathrm{FEV}_{1}$, morning peak expiratory flow, and ACQ-5 score. With MART, adolescents perceived benefits from the medication, thus helping to improve adherence. Therefore, this recommendation should probably be included in major clinical guidelines in the coming years.

Very interesting data on the use of ICS/LABA as needed in mild asthma (step 2) have been reported from the SYGMA (SYmbicort Given as needed in Mild Asthma) studies [7,24], which concluded that in patients with mild asthma (step 2), as-needed budesonide/formoterol controlled asthma symptoms better than as-needed terbutaline, although the approach was inferior to budesonide maintenance therapy. As-needed budesonide/formoterol also resulted in a $64 \%$ lower rate of severe exacerbations than as-needed terbutaline and did not differ significantly from budesonide maintenance therapy. In addition, budesonide/formoterol as needed resulted in substantially lower exposure to corticosteroids (less than one fifth) than budesonide maintenance treatment. Moreover, adverse effects were more frequent even in the terbutaline group (42\%) than in the budesonide/formoterol group (38\%) and the budesonide maintenance group (39.9\%). The results of this trial also suggest that as-needed budesonide/formoterol in 
mild asthma could address patients' concerns about the risks of treatment, which is yet another factor that causes overreliance on SABAs and poor adherence to maintenance treatment with ICSs $[24,27]$. The results of as-needed budesonide/formoterol compared with budesonide for maintaining asthma control could be explained by the higher rate of adherence than that observed in real-world populations, where adherence rates are considerably lower. As 2 strategies of treatment are compared (reliever vs maintenance), many patients may prefer to accept occasional mild symptoms as a driver of reliever use, if it frees them from daily use of ICSs.

Bateman et al [7] presented similar results in their doubleblind, randomized, parallel-group, 52-week, phase 3 trial. A total of 4215 patients were randomly assigned to receive twice-daily placebo plus budesonide/formoterol as needed or budesonide maintenance therapy with twice-daily budesonide plus terbutaline as needed. The results showed that in mild asthma, budesonide/formoterol used as needed was noninferior to twice-daily budesonide with respect to the rate of severe asthma exacerbations; this was achieved with less than one quarter of the total exposure to ICSs. However, findings for other endpoints such as control of asthma symptoms, quality of life, and $\mathrm{FEV}_{1}$ were superior with budesonide maintenance therapy than with budesonide/formoterol as needed [7].

Not receiving ICSs (because of lack of prescription, incorrect inhaler technique, or poor adherence) can be considered a risk factor for adverse asthma outcomes (exacerbations, persistent airflow limitation, and adverse effects of medication). In any case, ICSs do not improve symptom control $[16,17]$.

In conclusion, ICS/LABA therapy has proven to be more effective than SABA monotherapy as needed in step 2 and plays a role in improving adherence to ICSs.

\section{Dilemma 4: Reducing SABA to Feel Better?}

Treatment of asthma involves a personalized approach that includes education on self-management. Indications must be easy to understand not only for physicians, but also for patients. Although ICS/LABA as needed is more effective than SABAs, even in step 1 (see Dilemma 2), treatment with SABAs alone, if permitted, should only be administered in step 1 . The GINA guidelines recommend that SABA monotherapy should be restricted to patients who have symptoms less than twice per month, no waking due to asthma in the previous month, and no risk factors for exacerbations [5,6]. In fact, regular SABA treatment leads to rapid tolerance to $\beta_{2}$-receptors, rebound bronchoconstriction, and even increased inflammation [5].

When a patient is not well controlled, and it is decided to move to the next step of treatment, a dilemma arises: treatment must be adjusted by removing SABAs from maintenance therapy, yet SABAs are precisely the drugs that provide the greatest relief when the patient is experiencing increasingly severe symptoms as we step up. From step 2 onward, the main management guidelines recommend reduced use of SABAs, which, besides, is a criterion of control $[3,4]$. However, from the outset, we try to teach the patient to use SABAs as needed.
SABAs do not reduce the risk of flare-ups. Furthermore, there are no studies on long-term use of SABAs, adverse effects, or even tolerance. Patients with mild asthma tend to experience "SABAphilia", that is, they are addicted to SABAs because they achieve instant relief without the need for long-term treatment [3-5]. They feel it is a familiar, safe, and inexpensive treatment that controls their asthma. Therefore, when they start to experience the symptoms of an exacerbation, they tend to use SABAs instead of ICSs. This gives them the sensation (albeit erroneous) that they are better than they really are, as if they were at a lower step. This sensation is shared by physicians.

As mentioned above, it is very difficult for the patient to understand that SABAs are not the correct treatment from step 2 onward. Furthermore, as is the case with the treatment of almost all chronic diseases, and as a probable consequence, adherence to ICSs is very poor in adults and children [25], with an average dispensing coverage of $<25 \%$. Some studies claimed that, poor adherence to ICSs and overreliance on SABAs in adults and children are associated with an increased risk of severe exacerbation and death [16,28].

From step 2 of treatment onward, patients receive what appears to be conflicting advice for the self-administration of SABAs and LABAs. LABAs should never be used in monotherapy for asthma, but only in combination with an ICS (preferably in a single-inhaler combination). However, patients are commonly told to use SABAs as their only rescue medication. Evidence to date indicates that both SABAs and LABAs have serious risks as monotherapy, and there is no evidence to suggest any difference in the risks associated with regular "maintenance" use of either of them $[4,6]$.

In conclusion, we must ask whether SABA monotherapy could be the initial treatment for asthma, even in step 1, and whether it would be easier for the patient to understand that a combination of ICS/LABA on demand should be used from the beginning. In that way, we could prevent patients from experiencing SABAphilia.

\section{Dilemma 5: ICS/LABA Combination Therapy as Rescue Treatment}

The use of the combination of LABAs (formoterol) and ICSs delivered together for both maintenance and reliever therapy is known as MART. Despite the fact that all guidelines recommend MART (steps 3-6, GEMA; steps 3-5, GINA), current major guidelines show SABAs to be the preferred reliever drug, even though MART significantly reduces severe exacerbations and improves asthma control. There is even evidence that administration of budesonide/formoterol (via Turbuhaler) as MART is more effective than the regimen comprising fixed-dose ICS/LABA maintenance with asneeded SABA therapy in adults and children with chronic asthma. A meta-analysis summarizing the benefits of MART therapy compared with high-dose ICS/LABA reported an odds ratio for risk of exacerbations requiring hospitalization or visits to the emergency room of 0.72 (95\%CI, 0.57-0.90), whereas that for exacerbations requiring oral corticosteroids was 0.75 (95\%CI, 0.65-0.87) [26,29-31]. 
The ability of MART to reduce the number of days without receiving ICS therapy and the number of days with overuse of SABAs is associated with delay in obtaining medical help in both adults and adolescents with asthma [32]. Therefore, future international guidelines should reflect this evidence.

On-demand treatment according to severity of symptoms could be a problem for patients with a low perception of dyspnea or alexithymic patients [33]. However, this approach could lead to overtreatment, as occurs in asthmatic patients with obesity, one of the most frequent comorbidities of asthma [34].

\section{Dilemma 6: Can Immunotherapy Be Used in Poorly Controlled Asthma?}

Allergen-specific immunotherapy (AIT) is considered the only treatment capable of modifying the natural history of allergic respiratory disorders and would probably be more useful for patients with severe symptoms. It is a valuable therapeutic alternative in respiratory allergic diseases (rhinitis and/or asthma), and its use is recognized and recommended in evidence-based practice parameters and international guidelines $[3,4]$. Both study quality and the safety of subcutaneous immunotherapy are problematic. No guidelines consider AIT in patients with poorly controlled asthma, even though such an approach would be much more useful in this population than in patients whose disease is already controlled.

Immunotherapy (sublingual and subcutaneous) is recommended in mild-to-moderate allergic asthma to improve control and reduce exacerbations and the need for maintenance medication. However, recent studies have shown that sublingual immunotherapy (SLIT) with house dust mite (HDM) extract is safe and effective in patients with persistent poorly controlled asthma taking a medium to high dose of ICS $[27,35,36]$. While subcutaneous immunotherapy/ SLIT significantly improved symptom and medication scores compared with placebo or active comparators in respiratory allergy, adverse effects were reported. Although current evidence extracted from meta-analyses and systematic reviews shows AIT to be effective, relatively safe, and well-tolerated in some allergic diseases, differences between the studies and methodological inconsistencies may affect the validity and applicability of results, especially in real-life settings.

In a recent study by Virchow et al [37], the authors treated patients with moderate-persistent asthma (400-1200 $\mu$ g budesonide; approximately $40 \%$ of the participants used $800-1200 \mu \mathrm{g}$ of budesonide per day at randomization) and poorly controlled asthma (ACQ score between 1 and 1.5) with HDM-based SLIT. According to the GINA classification, $72 \%$ of participants had partly controlled asthma, and $28 \%$ of participants had uncontrolled asthma at randomization. SLIT enabled patients to reduce daily ICS use to $50 \%$ for 3 months. In addition, participants who did not experience an asthma exacerbation were subsequently able to discontinue their medication. The authors concluded that in adults with asthma related to HDM allergy that is not controlled by ICSs, the addition of HDMbased SLIT to maintenance medication improved time to first moderate or severe asthma exacerbation while the ICS dose was being reduced. However, to date, neither GINA [3] nor
GEMA [4] have provided indications for immunotherapy in patients with poorly controlled asthma.

The possible (although usually mild) adverse events related to AIT have limited its use to mild-to-moderate and controlled asthma. However, the potential efficacy and safety of AIT should be assessed in 2 specific situations: patients with well-controlled severe disease and patients with partially controlled severe disease who have received pretreatment or concomitant treatment with biologic drugs (eg, omalizumab, mepolizumab) [38].

The combination of AIT/omalizumab has been explored in a few trials involving asthma patients [39] and also in other allergic disorders, such as rhinitis, systemic reaction to hymenoptera venom, and food allergy [40,41], with significant and positive results.

\section{Dilemma 7: Allergic vs Nonallergic Asthma}

Finally, the differences between allergic and nonallergic asthma should be considered. Major asthma guidelines, such as GINA, do not distinguish between allergic and nonallergic types [3]. The concept of allergic respiratory disease is not even mentioned. This fact should be taken into consideration, because management across various levels of severity may differ in relevant aspects (eg, allergen avoidance, AIT, anti-IgE therapy), both in children and in adults [11,32]. Moreover, it has been reported that patterns of sensitization can lead to different presentations of respiratory disease $[32,43,44]$, and quality of life in patients with respiratory disease is influenced by clinical sensitization profiles [45].

Two consecutive, descriptive, noninterventional multicenter studies (PERFILAR I and II) used the ACG-5 test to assess disease control and the Mini-AQLQ and ESPRINT-15 instruments to assess quality of life. The authors concluded that different aeroallergens produce different sensitization profiles with different symptoms and different levels of severity and quality of life [43-45]. This observation is crucial if we are to ensure appropriate treatment and predict the disease course. Therefore, the role of the causative allergen in diagnosis and therapy should be reinforced, given the extent of the role of the allergen in disease duration and severity.

It is very important to obtain data on the characteristics of the culprit allergen(s) in allergic respiratory disease in order to apply avoidance measures and consider the indication of AIT. Such data would also make it possible to assess the start and duration of drug treatment, the potential impact on quality of life, and future risk.

\section{Conclusions}

Asthma management is based on standardized protocols, which are considered "best practice", as reflected in clinical guidelines. However, in a recent opinion paper, several experts in the field stated that when considering asthma treatment, clinicians usually focus on established asthma, rather than on the fundamental underlying causes [42]. This may have led us to overlook important etiological and pathogenic aspects of the 
disorder and to miss many of the variants encompassed by the broad term "asthma".

Asthma treatment involves both a personalized and a global approach: each patient is different, and the various aspects that must be taken into account, including self-management, a written action plan, management of comorbidities, and modifiable risk factors. This complexity and the lack of precise information on several aspects of the disease make it difficult to generalize recommendations while simultaneously trying to personalize treatment. It is perhaps unavoidable that contradictions and dilemmas arise with respect to diagnosis, management, and prognosis of the various types of asthma.

In this review, we present our opinion on the potential controversies and discrepancies that arise when treating patients in daily clinical practice. We believe that more and better tools are needed to achieve optimal control; these should probably be computerized or web-based. In addition, more studies are needed to clarify and define whether ICS/ LABA therapy should replace SABAs as reliever treatment and whether SABAs should always be combined with ICSs to treat inflammation from step 1.

More studies are needed to establish the safety and utility of AIT in poorly controlled asthma.

While we understand that these issues cannot be addressed in current evidence-based asthma guidelines, they should at least fuel the discussion on how to improve asthma management and to consider new paradigms to confront this complex respiratory disorder.

\section{Acknowledgments}

The authors would like to thank Content Ed Net Communications, S.L. for writing and editorial support.

\section{Funding}

The authors declare that no funding was received for the present study.

\section{Conflicts of Interest}

AV has served as a consultant to AstraZeneca, Novartis, Sanofi, and Mundipharma and received lecture fees from Chiesi, Novartis, AstraZeneca, Mundipharma, and GSK.

JO has served as a consultant to AstraZeneca and GSK and received lecture fees from Leti, AstraZeneca, Mundipharma, and Astra Zeneca.

JD has received speaker's honoraria from AstraZeneca, TEVA, Chiesi, Mundipharma, Pfizer, Leti, and Merck.

During the last 3 years, VP has received honoraria for speaking at sponsored meetings from AstraZeneca, Chiesi, GSK, and Novartis and financial assistance to travel to meetings from Chiesi and Novartis. VP has also acted as a consultant for ALK, AstraZeneca, Boehringer, MundiPharma, and Sanofi and received funding/grant support for research projects from a variety of government agencies and not-forprofit foundations, as well as from AstraZeneca, Chiesi, and Menarini.

FA has received financial support for attending congresses and lecture fees and has served as consultant for Alk-Abello,
AstraZeneca, Bial, Boheringer-Ingelheim, Chiesi, Menarini, Mundipharma, GSK, Novartis, Pfizer, and TEVA.

During the last 3 years, JM has received lecture fees from AstraZeneca, Boehringer-Ingelheim, GlaxoSmithKline, Menarini, and Roche. He has also received financial support for research projects from governmental agencies, scientific societies, and Boehringer-Ingelheim.

EM has received lecture fees and has served as consultant for Almirall, AstraZeneca, Boehringer Ingelheim, Chiesi, Gebro, GlaxoSmithKline, Intermune, Mundipharma, Novartis, Pfizer, Roche, Rovi, and Teva.

SQ has served as a consultant for AstraZeneca, Novartis, Sanofi, Genetech, Teva, ALK, Mundipharma, and GSK and received lecture fees from Chiesi, Novartis, GSK, Leti, AstraZeneca, Mundipharma, and GSK.

\section{References}

1. Croisant S. Epidemiology of asthma: prevalence and burden of disease. Adv Exp Med Biol. 2014;795:17-29.

2. Ghaffari J. The prevalence of children asthma: a few comments. Clin Respir J. 2018;12:2454

3. ( ${ }^{*}$ NEW) 2018 GINA Report: Global Strategy for Asthma Management and Prevention | Global Initiative for Asthma GINA [Internet]. [cited 2018 Jun 26]. Available from: https:// ginasthma.org/2018-gina-report-global-strategy-for-asthmamanagement-and-prevention/

4. Plaza Moral V, Alonso Mostaza S, Alvarez Rodríguez C, GomezOutes A, Gómez Ruiz F, López Vina A. Spanish guideline on the management of asthma. J Investig Allergol Clin Immunol. 2016;26 Suppl 1(Suppl 1):1-92.

5. Papi A, Brightling C, Pedersen SE, Reddel HK. Asthma. Lancet. 2018;391:783-800

6. O'Byrne PM, Jenkins C, Bateman ED. The paradoxes of asthma management: time for a new approach? Eur Respir J. 2017;50(3).

7. Bateman ED, Reddel HK, O'Byrne PM, Barnes PJ, Zhong N, Keen $\mathrm{C}$, et al. As-Needed Budesonide-Formoterol versus Maintenance Budesonide in Mild Asthma. N Engl J Med. 2018;378:1877-87.

8. Du W, Zhou L, Ni Y, Yu Y, Wu F, Shi G. Inhaled corticosteroids improve lung function, airway hyper-responsiveness and airway inflammation but not symptom control in patients with mild intermittent asthma: A meta-analysis. Exp Ther Med. 2017; 14:1594-608.

9. Schatz M, Sorkness CA, Li JT, Marcus P, Murray JJ, Nathan RA, et al. Asthma Control Test: reliability, validity, and responsiveness in patients not previously followed by asthma specialists. J Allergy Clin Immunol. 2006;117:549-56.

10. Juniper EF, O'Byrne PM, Guyatt GH, Ferrie PJ, King DR. Development and validation of a questionnaire to measure asthma control. Eur Respir J. 1999;14:902-7.

11. Mahdaviani SA, Mohajerani SA, Fakhri $M$, Ebrahimi $M$, Bashardoost B, Razavi SJ, et al. Allergic and nonallergic asthma in children: are they distinct phenotypes? Iran J Allergy Asthma Immunol. 2014;13:370-4.

12. Gutiérrez FJÁ, Galván MF, Gallardo JFM, Mancera MB, Romero $B R$, Falcón AR. Predictive factors for moderate or severe exacerbations in asthma patients receiving outpatient care. BMC Pulm Med. 2017;17:77. 
13. Quirce S, Delgado J, Entrenas LM, Grande M, Llorente C, López Viña A, et al. Quality Indicators of Asthma Care Derived From the Spanish Guidelines for Asthma Management (GEMA 4.0): A Multidisciplinary Team Report. J Investig Allergol Clin Immunol. 2017:27:69-73.

14. Munoz-Cano R, Torrego A, Bartra J, Sanchez-Lopez J, Palomino $R$, Picado $C$, et al. Follow-up of patients with uncontrolled asthma: clinical features of asthma patients according to the level of control achieved (the COAS study). Eur Respir J. 2017;49(3).

15. Olaguibel JM, Quirce $S$, Juliá B, Fernández C, Fortuna AM, Molina J, et al. Measurement of asthma control according to Global Initiative for Asthma guidelines: a comparison with the Asthma Control Questionnaire. Respir Res. 2012;13:50.

16. Jia CE, Zhang HP, Lv Y, Liang R, Jiang YQ, Powell $H$, et al. The Asthma Control Test and Asthma Control Questionnaire for assessing asthma control: Systematic review and metaanalysis. J Allergy Clin Immunol. 2013;131:695-703.

17. Deschildre A, Pin I, El Abd K, Belmin-Larrar S, El Mourad S, Thumerelle $C$, et al. Asthma control assessment in a pediatric population: comparison between GINA/NAEPP guidelines, Childhood Asthma Control Test (C-ACT), and physician's rating. Allergy. 2014;69:784-90.

18. Vennera M del C, Picado C, Herráez L, Galera J, Casafont J; Study Group CONTROL. Factors associated with severe uncontrolled asthma and the perception of control by physicians and patients. Arch Bronconeumol. 2014;50:38491.

19. Bidad N, Barnes N, Griffiths C, Horne R. Understanding patients' perceptions of asthma control: a qualitative study. Eur Respir J. 2018;51(6).

20. Nannini LJ, Neumayer NS. Treatment Step 1 for Asthma Should Not Be Left Blank, and SABA-Only Might Not Be a Treatment Step 1 Option for Asthma. Respiration. 2018;95:212-4.

21. Boushey HA, Sorkness CA, King TS, Sullivan SD, Fahy JV, Lazarus SC, et al. Daily versus as-needed corticosteroids for mild persistent asthma. N Engl J Med. 2005;352:1519-28.

22. Papi A, Canonica GW, Maestrelli P, Paggiaro P, Olivieri D, Pozzi $E$, et al. Rescue Use of Beclomethasone and Albuterol in a Single Inhaler for Mild Asthma. N Engl J Med. 2007;356:204052.

23. Calhoun WJ, Ameredes BT, King TS, Icitovic N, Bleecker ER, Castro M, et al. Comparison of physician-, biomarker-, and symptom-based strategies for adjustment of inhaled corticosteroid therapy in adults with asthma: the BASALT randomized controlled trial. JAMA. 2012;308:987-97.

24. O'Byrne PM, FitzGerald JM, Bateman ED, Barnes PJ, Zhong $\mathrm{N}$, Keen $\mathrm{C}$, et al. Inhaled Combined Budesonide-Formoterol as Needed in Mild Asthma. N Engl J Med. 2018;378:186576.

25. Boulet $L P$, Vervloet $D$, Magar $Y$, Foster JM. Adherence: the goal to control asthma. Clin Chest Med. 2012;33:405-17.

26. Jorup C, Lythgoe D, Bisgaard H. Budesonide/formoterol maintenance and reliever therapy in adolescent patients with asthma. Eur Respir J. 2018;51(1).

27. Wang L, Yin J, Fadel R, Montagut A, de Beaumont O, Devillier P. House dust mite sublingual immunotherapy is safe and appears to be effective in moderate, persistent asthma. Allergy. 2014;69:1181-8.
28. Araújo L, Jacinto T, Moreira A, Castel-Branco MG, Delgado L, Costa-Pereira A, et al. Clinical efficacy of web-based versus standard asthma self-management. I Investig Allergol Clin Immunol. 2012;22:28-34.

29. Beasley R, Braithwaite I, Fingleton J, Weatherall M. The inhaled corticosteroid/long-acting $\beta$-agonist maintenance and reliever therapy regimen: where to from here? Eur Respir J. 2018;51(1).

30. Kew KM, Karner C, Mindus SM, Ferrara G. Combination formoterol and budesonide as maintenance and reliever therapy versus combination inhaler maintenance for chronic asthma in adults and children. Cochrane Database Syst Rev. 2013; CD009019.

31. Patel M, Pilcher J, Pritchard A, Perrin K, Travers J, Shaw D, et al. Efficacy and safety of maintenance and reliever combination budesonide-formoterol inhaler in patients with asthma at risk of severe exacerbations: a randomised controlled trial. Lancet Respir Med. 2013;1:32-42.

32. Navarro AM, Delgado J, Muñoz-Cano RM, Dordal MT, Valero A, Quirce S; Behalf of the ARD Study Group. Allergic respiratory disease (ARD), setting forth the basics: proposals of an expert consensus report. Clin Transl Allergy. 2017;7:16.

33. Plaza V, Giner J, Picado C, Sureda B, Serrano J, Casan P, et al. Control of ventilation, breathlessness perception and alexithymia in near-fatal asthma. J Asthma. 2006;43:639-44.

34. Garcia Rio F, Alvarez Publa M, Esteban I, Barranco P, Olaguibel J. Obesity and asthma. Key clinical questions. J Investig Allergol Clin Immunol. 2018; doi: 10.18176/jiaci.0316. [Epub ahead of print].

35. Prieto L. Tablet-based sublingual immunotherapy for respiratory allergy. Allergol Immunopathol (Madr). 2017;45 Suppl 1:30-5.

36. Halken $S$, Larenas-Linnemann $D$, Roberts $G$, Calderón $M A$, Angier $E$, Pfaar 0 , et al. EAACl guidelines on allergen immunotherapy: Prevention of allergy. Pediatr Allergy Immunol. 2017;28:728-45.

37. Virchow JC, Backer V, Kuna P, Prieto L, Nolte H, Villesen HH, et al. Efficacy of a House Dust Mite Sublingual Allergen Immunotherapy Tablet in Adults with Allergic Asthma: A Randomized Clinical Trial. JAMA. 2016;315:1715-25.

38. Braido F, Corsico A, Rogkakou A, Ronzoni V, Baiardini I, Canonica GW. The relationship between allergen immunotherapy and omalizumab for treating asthma. Expert Rev Respir Med. 2015;9:129-34.

39. Moscato G, Pala G, Sastre J. Specific immunotherapy and biological treatments for occupational allergy. Curr Opin Allergy Clin Immunol. 2014;14:576-81.

40. Lin C, Lee IT, Sampath V, Dinakar C, DeKruyff RH, Schneider LC, Nadeau KC. Combining anti-IgE with oral immunotherapy. Pediatr Allergy Immunol. 2017;28:619-27.

41. Labrosse R, Graham F, Des Roches A, Bégin P. The use of omalizumab in food oral Immunotherapy. Arch Immunol Ther Exp (Warsz). 2017;65:189-99.

42. Pavord ID, Beasley R, Agusti A, Anderson GP, Bel E, Brusselle $G$, et al. After asthma: redefining airways diseases. Lancet. 2018;391:350-400.

43. Domínguez-Ortega J, Quirce S, Delgado J, Dávila I, MartíGuadaño E, Valero A. Diagnostic and therapeutic approaches in respiratory allergy are different depending on the profile 
of aeroallergen sensitization. Allergol Immunopathol (Madr). 2014;42:11-8.

44. Valero A, Quirce S, Dávila I, Delgado J, Domínguez-Ortega J. Allergic respiratory disease: Different allergens, different symptoms. Allergy. 2017;72:1306-16.

45. Delgado J, Dávila I, Domínguez-Ortega J, Quirce S, MartíGuadaño E, Valero A. Quality of life in patients with respiratory allergy is infuenced by the causative allergen. I Investig Allergol Clin Immunol. 2013;23:309-14.

\section{Santiago Quirce}

Department of Allergy

Hospital La Paz Institute for Health Research (IdiPAZ) and CIBER de Enfermedades Respiratorias (CIBERES)

Madrid, Spain

E-mail: santiago.quirce@salud.madrid.org 